\title{
Failure Analysis of Centre Pin Joint Used In Heavy Assault Bridge
}

\author{
Dnyaneshwar J. Sushir ${ }^{1}$, Prashant N. Ulhe ${ }^{2}$ \\ I'Mechanical Engg. Department, SSBT's COET, Bambhori, Jalgaon / North Maharashtra University, India) \\ ${ }^{2}$ (Mechanical Engg. Department, SSBT's COET, Bambhori, Jalgaon / North Maharashtra University, India)
}

\begin{abstract}
Strategy is important to win the war in army. Every army has two major divisions as infantry and artillery. Artillery is dependent on the armored vehicles such as tanks, missile carriers and trucks. The movement of armored vehicles has vital importance in war to win. In order to cross the obstacles such as rivers, canals army has to build arrangement which will be quicker and faster to construct the bridge. These kinds of quickly constructed bridges are known as Heavy Assault Bridge. Its job is to allow armored units to cross the obstacles. The Heavy Assault bridge is rated for normal crossings of military load classification of 60 tons.

Centre Pin Joint is placed between modules of the girders in a single bridge span. The maximum stresses will develop at centre pin joint only. Before failure of bridge centre pin joint will fail. So proper centre pin design is the main criteria. The objective of this project is to perform a failure analysis of the centre pin joint used in heavy assault bridge. So it is very important to determine high-stress areas of concern and to increase its load carrying capacity by design modification. As previously centre pin joint is replaced by modified pin joint, its load carrying capacity will be enhanced. Riveting of pin would be eliminated. Finally, conclusions based on the results and recommendations which can be extensions of this project are also presented.
\end{abstract}

Keywords - Heavy assault bridge, Centre pin joint, Ansys.

\subsection{BACKGROUND:}

\section{INTRODUCTION}

A "Heavy Assault Bridge (HAB)" is a combat support vehicle sometimes regarded as a subtype of combat engineering vehicle designed to assist militaries in rapidly deploying tanks and other armored to cross the obstacles. The HAB is usually a tracked vehicle converted from a tank chassis to carry a folding metal bridge instead of a turret. The job of HAB is to allow armored or infantry units to cross obstacles when it is too deep and no bridge is conveniently located.

The bridge layer unfolds and launches its cargo providing a ready-made bridge across the obstacle in only minutes. Once the span has been put in place, the HAB vehicle detaches from the bridge and moves aside to allow traffic to pass. Once all of the vehicles have crossed, it crosses the bridge itself and reattaches to the bridge on the other side. It then retracts the span ready to move off again. A similar procedure can be employed to allow crossings of similar obstructions.

Mostly today HAB can carry bridges of 60 feet (19 meters) or greater in length. By using a tank chassis the bridge layer is able to cover the same terrain as main battle tanks and the provision of armor allows them to operate even in the face of enemy fire. However this is not a universal attribute design, specification, implementation changes according to terrain and area of implementation.

\subsection{OBJECTIVES OF THE STUDY:}

\subsubsection{General Objective:}

The objective of the study is to produce results which may help to rectify problems associated with the centre pin joint used in heavy assault bridge and which also may be of significance during design of the centre pin joint after carrying out static analysis, combining existing theoretical knowledge and advanced analytical methods to improve the load carrying capacity of the centre pin joint by design modifications.

\subsubsection{Specific Objectives:}

I. To develop mathematical and finite element model of the major components of a centre pin joint used in heavy assault bridge and carry out static analysis of the structures.

II. Based on the analysis, identify points and sections which are highly loaded (stressed) due to the loads by means of which the overall intensity of loading in the structures is assessed.

III. Improve the load carrying capacity of the centre pin joint by design modifications.

Iv.Arrive at conclusions and propose recommendations.

1.3 METHODOLOGY: To fulfill the objectives of the study the following are used. 
I. Literature Review: Survey of books, journal articles, proceedings of international Conferences, manufacturer catalogues, and other relevant literatures are done.

II. Data Collection: Data regarding the centre pin and the heavy assault bridge are collected. The data include dimensions of the structure, material used to construct the structure and construction methods.

III. Modeling and Analysis: The finite element model development as well as the corresponding static analysis is performed using ANSYS software.

IV. Conclusions and Recommendations.

\subsection{ORGANIZATION OF THE THESIS:}

The body of this thesis is divided into eight main chapters. The first chapter discusses background and objectives of the study. In addition, the details of the Indian bridges are used in the analysis are also discussed in the same chapter. The second chapter covers the review of some of the journal articles, proceedings and publications which were referred during the course of the thesis. Also, in relation and comparison with previous works, what is done in this thesis will be stated. The mathematical and finite element modeling is discussed in the sixth chapter. Also, covered in this chapter is meshing of the solid model of the centre pin joint used for the analysis into finite elements and the mathematical formulation of these elements. The results obtained from the static analysis of the centre pin joint and discussions based on these results are included in the eighth chapter. Finally, the eighth chapter covers conclusions drawn based on the results of the analysis and recommendations for future work.

\subsection{Origin:}

\section{LITERATURE REVEIW}

The roots of the modern HAB can be found in World War I, at the dawn of tank warfare. Having developed tanks, the UK and France were confronted with the problem of mounting tank advances in the face of the trenches that dominated the battlefields. Early engagements, such as at Cambria demonstrated the tank's utility, but also highlighted its vulnerability to battlefield geography many early tanks found themselves ignominiously stuck in the trenches, having insufficiently long tracks to cross them. To counter this disadvantage, tanks (especially the common British Mark series) began to go into battle with fascines hanging over their bows, sometimes as simple as a bundle of heavy sticks. By dropping these into the trenches, they were able to create a wedge over which the tank could drive. Later, some tanks began to carry rails on their decks the first HAB.

\subsection{WORLD WAR II:}

It was in the World War II era that the importance of armored bridge layers, as well as combat engineering vehicles and armored became fully clear. With the advent of Blitzkrieg warfare, whole divisions had to advance along with tanks, which were suddenly far out-pacing the speed of infantry soldiers. Besides leading to the advent of self-propelled artillery/assault guns, mobile anti-aircraft and armored cars, it became clear that functions like vehicle repair, mine-clearing, and the like would have to be carried out by armored vehicles advancing along with tanks. Moreover, these forces would have to be able to cross all forms of terrain without losing speed and without having to concentrate their thrusts over certain bridges (and the rising weight of armored vehicles meant that fewer and fewer bridges could support these massed crossings). The only feasible solution to the dilemma posed by the mobility of all mechanized armed forces was a dedicated platform that could improvise river and obstacle crossings at short notice and in otherwise inconvenient locations. Tracked and armored, it was capable of operating right alongside combat units, crossing rough terrain and advancing in the face of light fire. To maximize on common parts and ease maintenance complications, they were usually based on existing tank chassis.

\subsection{INDIAN HAB:}

The Indian military bridging program is notable for several reasons. One is that it is in every sense a program \& not just a series of isolated projects carried out simultaneously. Almost every aspect of military bridging is being tackled from assault bridging to lines of communication structures bringing an opportunity to make maximum use of common components, materials, operating methods and other cost-saving measures. It is also interesting to note that not just bridging is included. Also involved in the program is an Armored Amphibious Dozer \& an Engineer Reconnaissance Vehicle (both based on the locally built BMP-2 Infantry Combat Vehicle chassis). Both are still comparative rarities elsewhere as few armies seem to take the trouble to procure such specialized vehicles.

One further aspect of the Indian bridging program is the involvement of industrial concerns in the design, development and learning curve relating to the program. From the earliest stages of the program those expected to manufacture the final products have been involved at every stage of the development process. Once 
again the cost-effectiveness advantages of such a process are many but it makes an interesting aside to consider that such a course of action is open only to a highly centralized defense infrastructure. The usual round of tenders and costly in-house developments associated with the now common place procurement programs carried out by most open market nations, especially in the United Kingdom.

\section{METHADOLOGY AND ANALYSIS \\ 3.1 FINITE ELEMENT METHOD:}

The Basic concept in FEA is that the body or structure may be divided into smaller elements of finite dimensions called "Finite Elements". The original body or the structure is then considered as an assemblage of these elements connected at a finite number of joints called "Nodes" or "Nodal Points". Simple functions are chosen to approximate the displacements over each finite element. Such assumed functions are called "shape functions". This will represent the displacement within the element in terms of the displacement at the nodes of the element.

Due to high cost of computing power of years gone by, FEA has a history of being used to solve complex and cost critical problems. Classical methods alone usually cannot provide adequate information to determine the safe working limits of a major civil engineering construction or an automobile or an aircraft. In the recent years, FEA has been universally used to solve structural engineering problems. The departments, which are heavily relied on this technology, are the automotive and aerospace industry. Due to the need to meet the extreme demands for faster, stronger, efficient and lightweight automobiles and aircraft, manufacturers have to rely on this technique to stay competitive.

If one needs to evaluate the area of the circle without using the conventional formula, one of the approaches could be to divide the above area into a number of equal segments; the area of each triangle multiplied by the number of such segments gives the total area of the circle.

\subsection{THE BASIC STEPS INVOLVED IN FEA:}

Mathematically, the structure to be analyzed is subdivided into a mesh of finite sized elements of simple shape. Within each element, the variation of displacement is assumed to be determined by simple polynomial shape functions and nodal displacements. Equations for the strains and stresses are developed in terms of the unknown nodal displacements. From this, the equations of equilibrium are assembled in a matrix form which can be easily be programmed and solved on a computer. After applying the appropriate boundary conditions, the nodal displacements are found by solving the matrix stiffness equation. Once the nodal displacements are known, element stresses and strains can be calculated.

\section{Basic Steps in FEA:}

3.2.1 Discretization of the domain

3.2.2 Application of Boundary conditions

3.3.3 Assembling the system equations

3.2.4 Solution for system equations

3.2.5 Post processing the results.

The first two steps of the above said process is known as pre-processing stage, third and fourth is the processing stage and final step is known as post-processing stage.

\subsection{THEORIES OF FAILURE:}

Determining the expected mode of failure is an important first step in analyzing a part design. The failure mode will be influenced by the nature of load, the expected response of the material and the geometry and constraints. In an engineering sense, failure may be defined as the occurrence of any event considered to be unacceptable on the basis of part performance. The modes of failure considered here are related to mechanical loads and structural analysis. A failure may include either an unacceptable response to a temporary load involving no permanent damage to the part or an acceptable response, which does involve permanent, and sometimes catastrophic, damage. The purpose of theories of failure is to predict what combination of principal stresses will result in failure. There are number of theories to describe failure criteria, of them these are the widely accepted theories.

\subsection{Choice of the theories of failure:}

Well documented experimental results by various authors on the various theories of failure, indicate that the distortion energy theory predicts yielding with greatest accuracy. Compared to this maximum shear stress theory predicts results which are always on safer side. Maximum principal stress theory gives conservative results only if the sign of the two principal stresses is the same (2-D case). Therefore, the use of 
maximum principal stress theory for pure torsion is ruled out where the sign of the two principal stresses are opposite.

When the fracture of a tension specimen loaded up to rupture is examined, it shows that for ductile materials, failure occurs along lines at angles 45 degrees with the load axis. This indicates a shear failure. Brittle materials on the other hand, rupture on planes normal to the load axis, indicating that maximum normal stress determines failure. Because of the above mentioned observations, it is universally accepted that for a brittle materials, the maximum normal stress theory is the most suitable. For ductile materials, the maximum shear stress theory gives conservative results and it is simpler to use as compared to distortion energy theory, so it is universally accepted as the theory of failure for ductile materials. But, where low weight is desired, the distortion energy theory is recommended.

\subsection{DESIGN REQUIREMENTS:}

\section{Physical AND Mathematical Modelling}

Maximum weight carried by bridge is of armored tank Arjun MBT. So, maximum load which will pass over the HAB is of Arjun MBT. The total weight of Arjun MBT is 64.5 tones. Therefore HAB should be design to withstand the maximum load of 70 tones.

Major components of HAB:

There are two major components in HAB,

4.1.1 Span (it is track over which vehicle will move)

4.1.2 Centre pin joint

A main pin joint in HAB Bridge is responsible for connecting two girders in a single bridge span. Simultaneously, it is the most loaded part during the launched operation under the obstacle and moving the vehicles through the main tracks of the bridge.

When load is applied on HAB, centre pin joint will fail before failure of span.

\subsection{LOAD CALCULATION:}

The weight of $18 \mathrm{G} 2 \mathrm{~A}$ steel is more as its density is high. But it won't make any kind of differences as total weight of centre pin joint is very small as compared to weight of HAB.

Strength:Ultimate strength of steel is very high upto $610 \mathrm{MPa}$.

Young's modulus is considered as $204000 \mathrm{MPa}$

Yield strength $398 \mathrm{MPa}$

Poison ratio 0.3

The Endurance Limit:

Following figure suggests that the endurance limit ranges from about 40 to $60 \%$ of the tensile strength for steel up to (1460 MPa)

About $1460 \mathrm{MPa}$, the scatter appears to increase, but the trend seems to level off at e S =740 MPa.

\subsection{TOTAL LOAD ON CENTRE PIN JOINT :}

\section{ANALYSIS AND RESULTS}

Weight of bridge is approximately 20 tons.

Armored vehicle passed over bridge it may weight approximately 60 tons.

Total weight on bridge is now 80 tons.

So, $80000 \times 9.81=784800 \mathrm{~N}$.

As there are two track, and bridge and vehicle passed over bridge are in symmetry, so load on single track will be half, $392400 \mathrm{~N}$.

Now, track is divided into two span, so load on single span is half, $196200 \mathrm{~N}$.

Again, each span will have two centre pin joint, therefore load on single centre pin joint element is $98100 \mathrm{~N}$.

Considering additional load on centre pin joint,

Total load on centre pin joint element is $=100000 \mathrm{~N}$.

\subsection{MATHEMATICAL PROOF :}

Development of shear stress :

Load on pin is $100000 \mathrm{~N}$

Inside diameter of hole is $40 \mathrm{~mm}$ and thickness of outside Lug is $12 \mathrm{~mm}$.

For one Lug element, Considering the YZ plane

Shear stress will be developed Inside the diameter of Lug,

Inside Area of Lug = Inside perimeter of hole $\mathrm{x}$ thickness of Lug

Inside perimeter of hole $=2 \times \pi \times r$

Inside Area of Lug $=2 \times 3.14 \times 20 \times 12=1507.2 \mathrm{~mm} 2$. 
Load on pin $=$ cross sectional area along YZ plane of hole $\mathrm{x}$ shear stress $100000=2 \times 3.14 \times 20 \times 12 \times$ shear stress

Shear stress along YZ plane $=67 \mathrm{MPa}$

Stress developed in Lug,

For existing central pin joint, as Lug size is Small and it is attached to welding surface area, therefore failure or maximum stress development will be at joining of Lug and welding surface.

Load on pin $=$ cross sectional area of Lug at joint $\mathrm{x}$ shear stress

$100000=12 \times 12 \times$ shear stress

Shear stress along YZ plane $=694 \mathrm{MPa}$.

5.3 MODIFIED CENTRE PIN JOINT: In this pin joint, lugs are long enough and welding surface area is same and is attached over lugs. Therefore according to geometry of figure maximum stress concentration will be at hole. But due to pin inside hole and no opportunity for lug to rotate, then it is to be said constrained. Hence hole is completely constrained. Due to perpendicular load on cross sectional area from hole to outer diameter of lug will be in double shear. So stress development will be half.

Load on one side of lug $=$ cross sectional area of lug from hole to outer diameter $\mathrm{x}$ stress

$100000=12 \times 30 \times$ stress $/ 2$

Stress developed inside hole is $=555 \mathrm{MPa}$.

\subsection{ANSYS RESULT :}

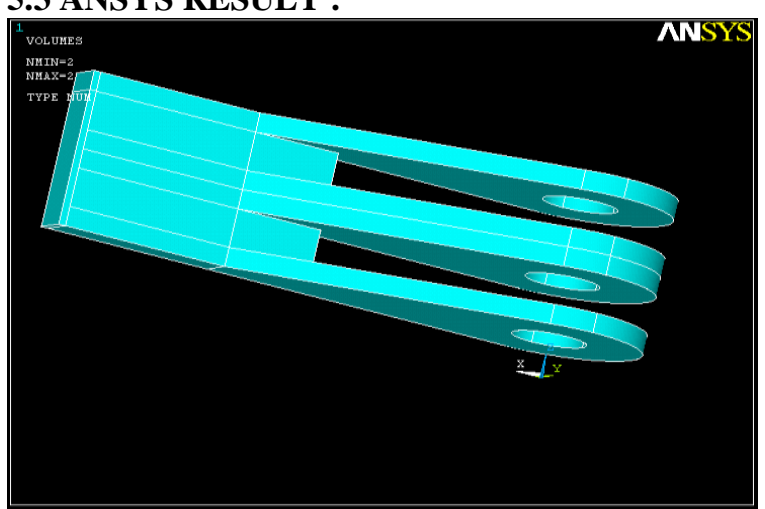

"Fig.1": Three Lugs Element

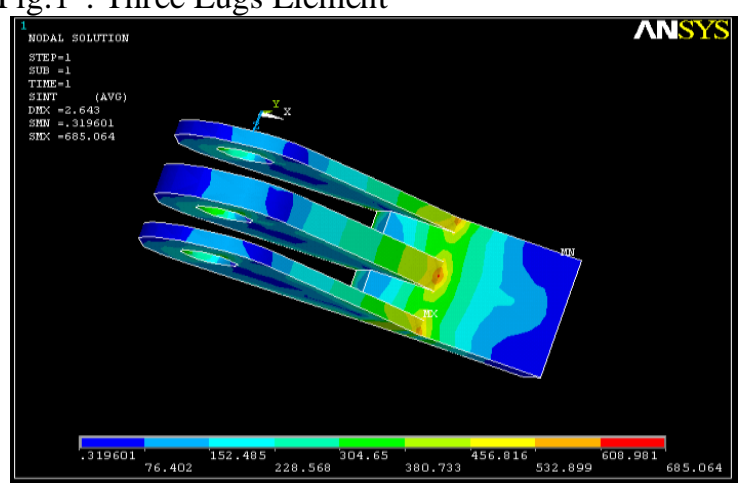

"Fig.3": Stress Intensity

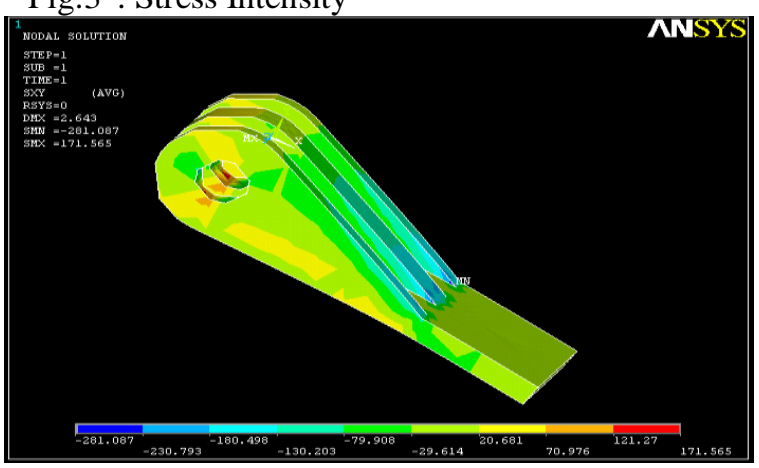

"Fig.5": Shear Stress along XY Axis

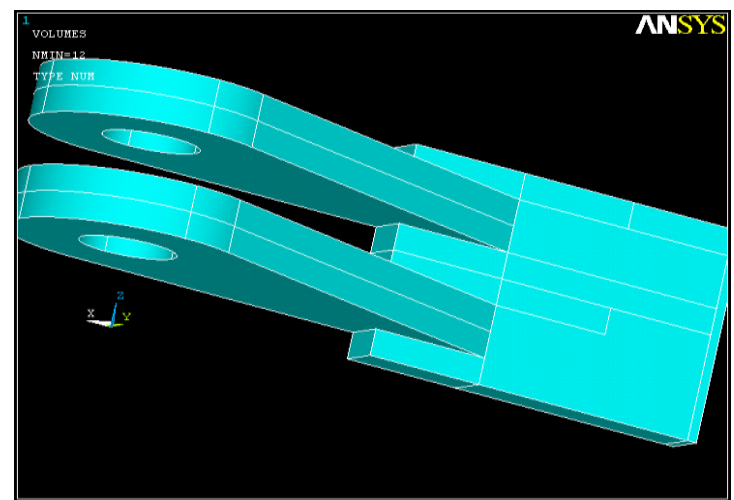

"Fig.2": Two Lugs Element

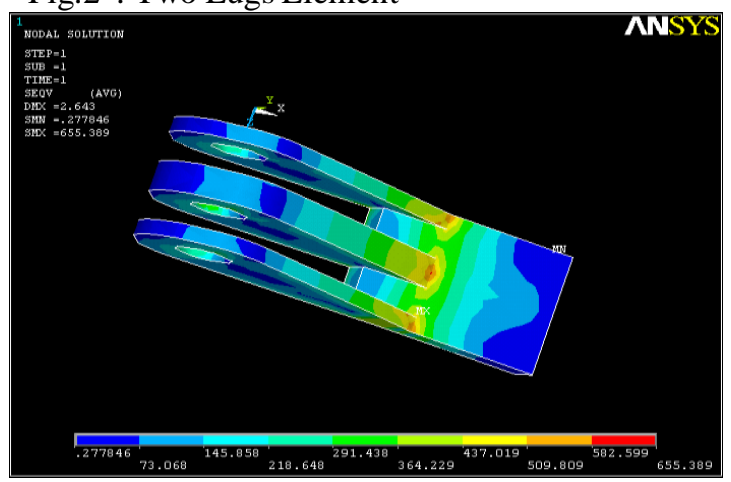

"Fig.4": Von-Misses Stress

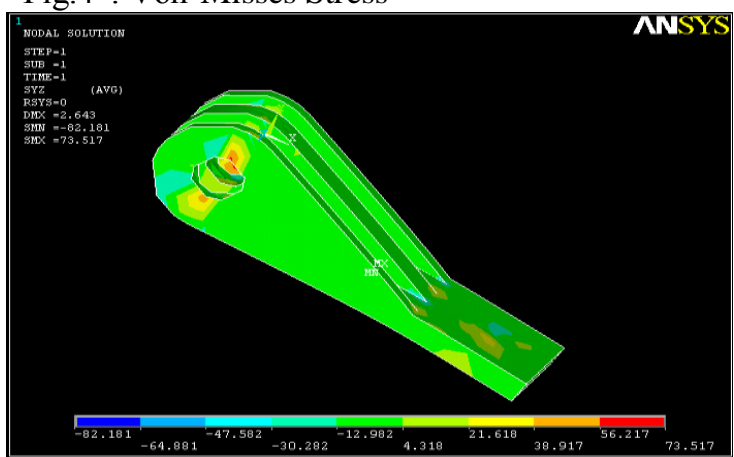

"Fig.6": Shear Stress along YZ axis 

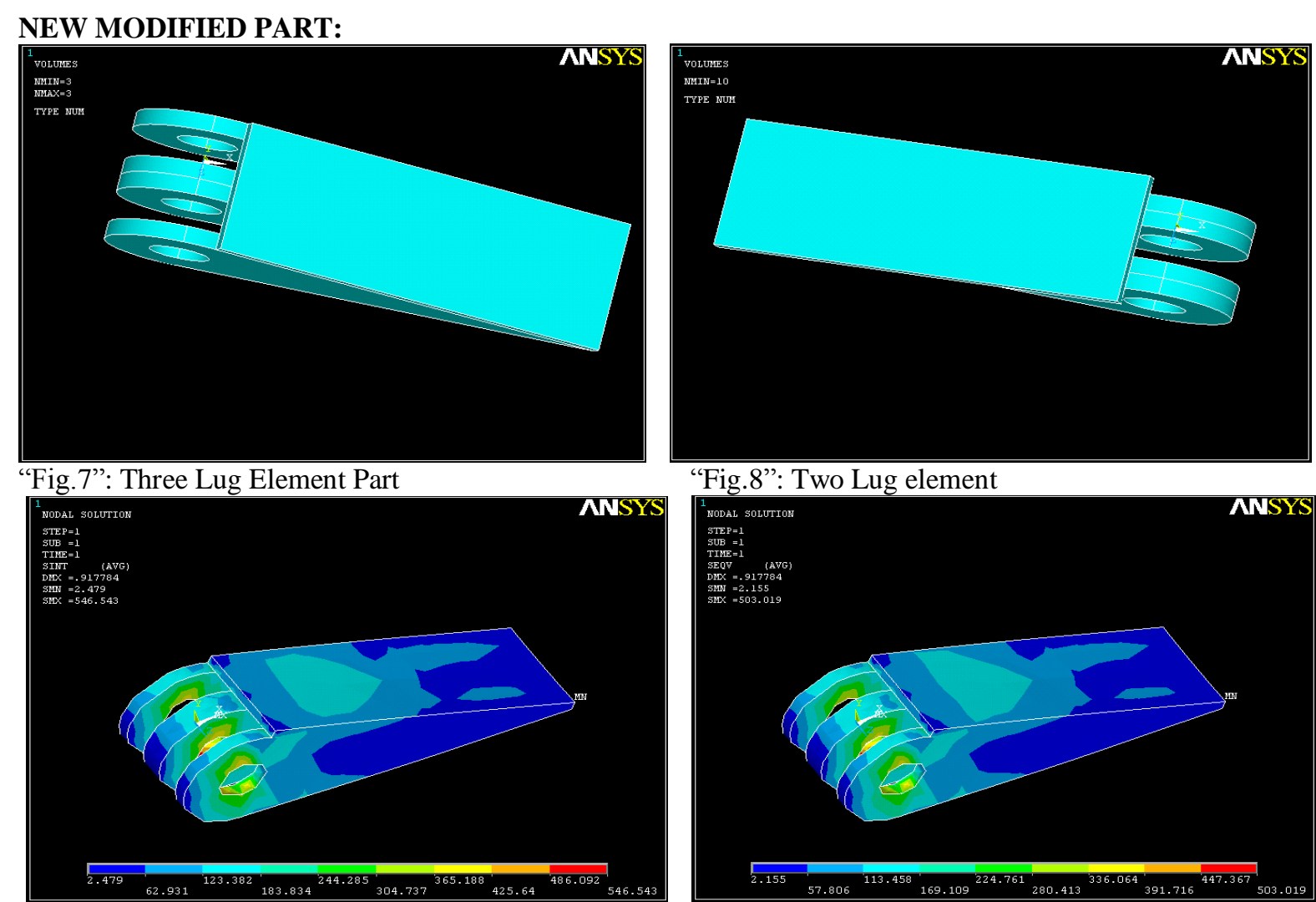

"Fig.8": Two Lug element
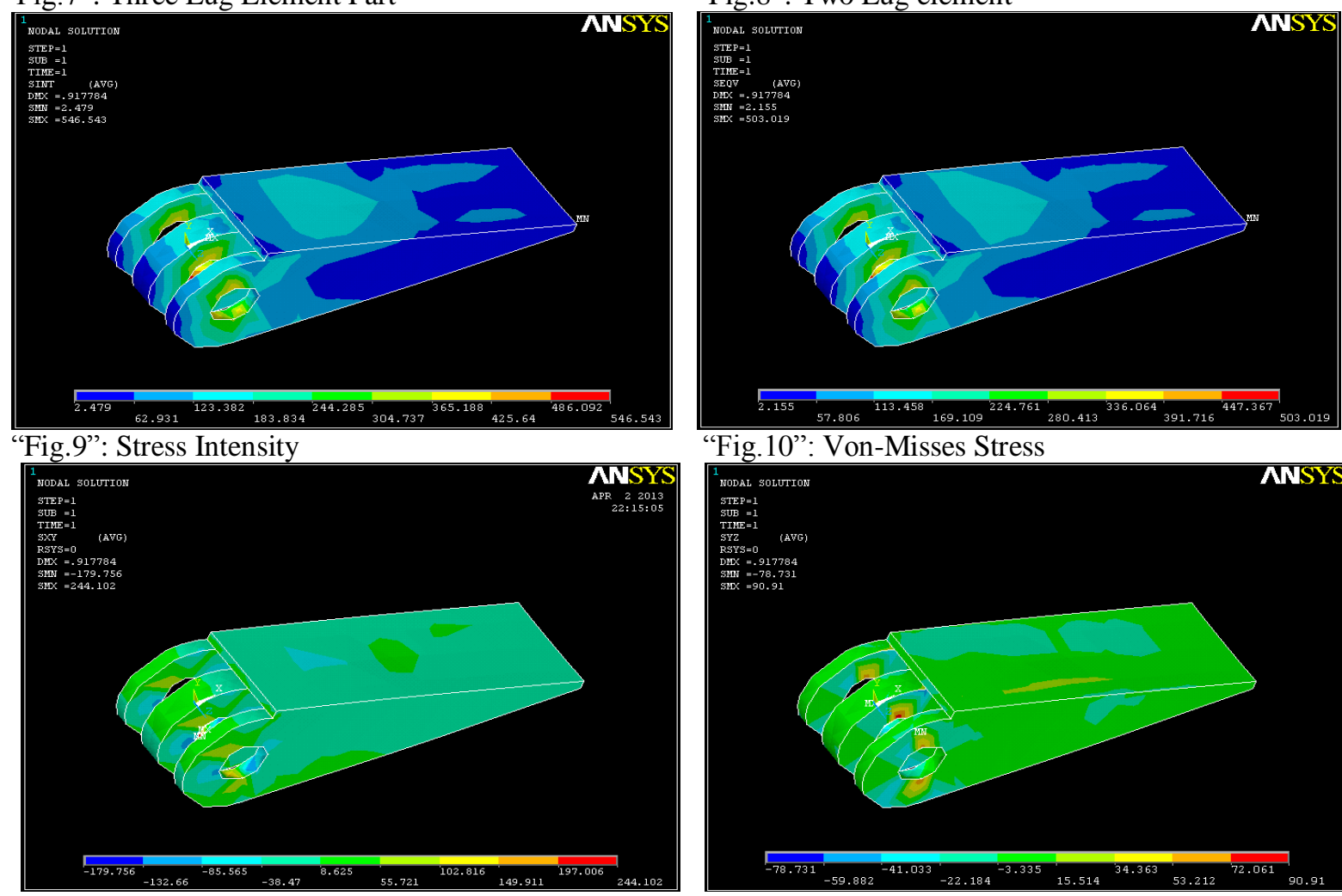

"Fig.11": Shear Stress along XY Axis

"Fig.12": Shear Stress along YZ Axis

Drawing of existing and modified part:

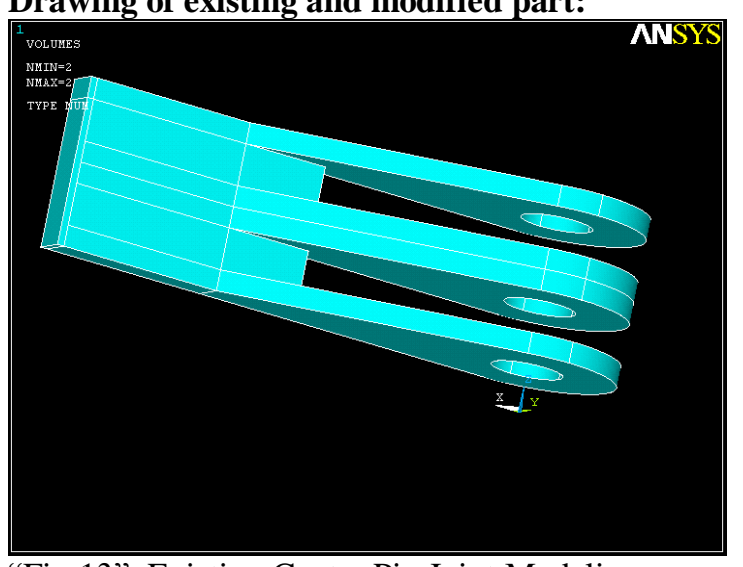

VI. Result:

"Fig.13": Existing Centre Pin Joint Modeling

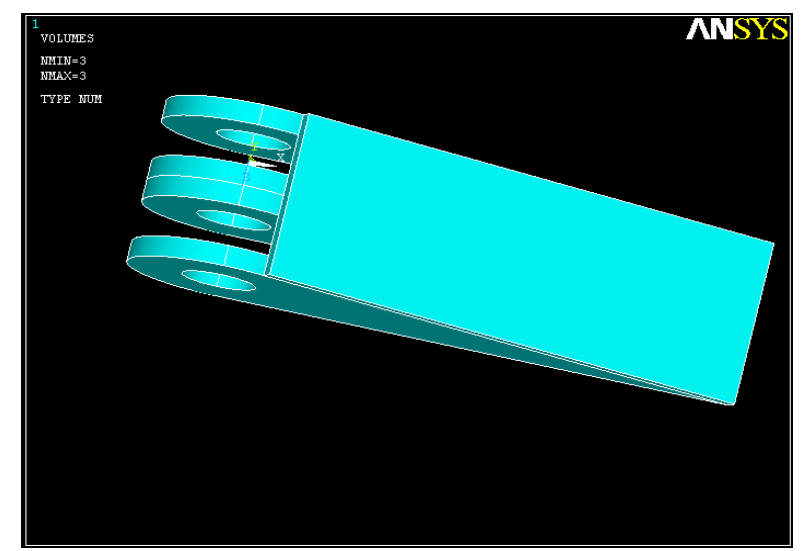

"Fig.14": Modified Centre Pin Joint Modeling 


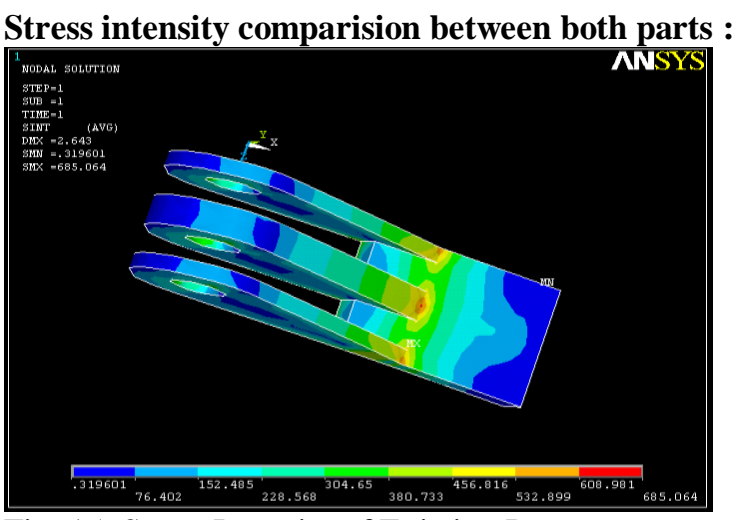

Fig. 15: Stress Intensity of Existing Part

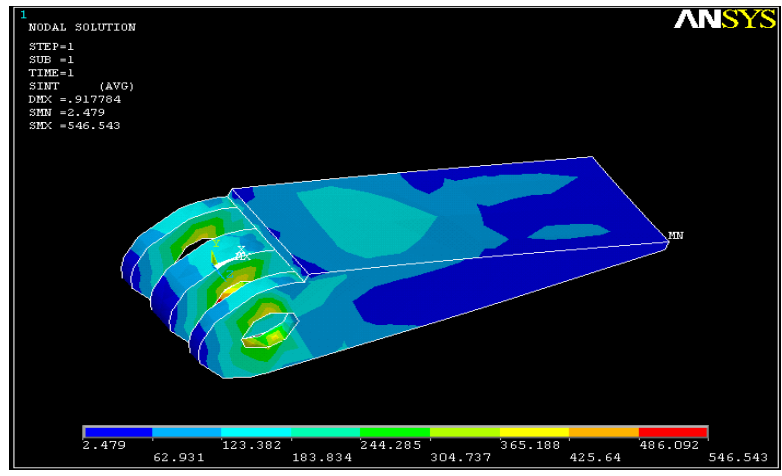

Fig. 16: Stress Intensity of Modified Part

Now we have following data,

\section{CONCLUSION}

$\mathrm{Sut}=610 \mathrm{MPa}$

Sy $=398 \mathrm{MPa}$

After $10^{4}=515 \mathrm{MPa}$

By comparing stress intensity of existing and modified part, the maximum stress developed in existing part is between the ranges of 609 to $685 \mathrm{MPa}$. And maximum ultimate stress of 18G2A steel is $610 \mathrm{MPa}$. For existing centre pin joint, stress limit slightly exceeds than ultimate stress which may cause sudden failure of existing centre pin joint fewer than 80 tones load including 20 tones bridge weight itself. So near about 60 tones weighted vehicle does not allow to pass over bridge. And it is limited upto 50 tones load.

For newly designed centre pin joint stress developed in part is between the range of 486 to $546 \mathrm{MPa}$ which is quite low as compared to ultimate stress and near about yield strength. So modified centre pin joint is sufficient safe for 60 tones weighted vehicle for passing over it.

\section{Acknowledgements}

First of all, I thank God for giving me the strength to accomplish this thesis. I express my sincere thanks with deep sense of gratitude of my Guide Prof. P.N.Ulhe for his encouragement, valuable suggestions, guidance and help throughout the preparation of this project.

I would like to express my deepest appreciation towards Dr.D.S.Deshmukh (H.O.D. Mechanical Engineering Department) whose valuable guidance supported me in preparing the report. I would also like to express my respect and gratitude to Principal of College for providing me this opportunity to prepare the project-I report.

I take this opportunity to thanks all the professors and staff members of Mechanical Engineering Department who have directly or indirectly helped me for the completion of the project. I am also grateful to other friends of mine who have been very cooperative.

Finally, thanks are due to my mother and father, Dwarkabai and Jagannath and my wife, Dr.Shital for her support and encouragement.

\section{REFERENCES}

[1] Department of the Army, 1990,"TM5-5420-203, Technical Manual: Operator's Unit, Direct Support and General Support Maintenance for Bridge, Armored Vehicle Launched: Scissoring Type: Class 60 and Class 70 Aluminium; 60 Foot Span; For M48A5 and M60 Launcher, MLC60 and MLC70," Headquarters, Department of the Army, Washington, D.C.

[2] Choi, Jeong-Hoon, 2000,"The Fracture Analysis and Remaining Life Estimation of the HAB Sub-Components," Master Thesis submitted to West Virginia University 5. Lewis R., 1987, "Production line applications of automated NDT systems," IEE.

[3] H.V.S. Ganga Rao, P. Klinkhachorn, U.B. Halabe, R.H.L. Chen, R. Kalluri, Alluri, E.S. Sazonov and J.H. Choi, "Damage and remaining life assessment for AVLB", Constructed Facilities Centre, West Virginia University, 2001, Submitted to U.S. Army TankAutomotive and Armament Command Acquisition Center, U.S. Army grant DAAE07-96-C-x226.

[4] Krason W. and Filiks L., Rigid and deformable models in the numerical strength test of Scissor Bridge.

[5] Dacko M., Krason W. and Filiks L., Experimental and numerical testing of the modernized BLG-67 Bridge.

[6] Reference manual, ANSYS, Version 12.

[7] Sienkiewicz O.C. and Taylor R.L., The Finite Element Method, Vol.1: The Basis, fifth edition, Butterworth-Heinemann, Oxford, 2000.

[8] Ministry of National Defense in India: Military Bridges, Manual, published by DRDO.

[9] Operational Manual: Trilateral design and test code for military bridging and gap-crossing equipment, Publisher in the United States, 1996.

[10] Indian Heavy Assault Bridge Kartik.

[11] Bridge fatigue life indicating system, By D. Thomson \& G. samavedam, Sep 1991.

12) Experimental and Numerical studies of the scissors HAB Type Bridge, by Wieslaw Krason \& Jerzy Malachowski Jan 2010. 